\title{
Margarita GonzÁlez, Pionera Y MAESTRA DE LA MODERNA REFLEXIÓN HISTÓRICA
}

José Eduardo Rueda Enciso

Escuela Superior de Administración Pública (ESAP),

Colombia. Grupo de Investigación Histórica sobre Problemática Pública "Radicales y Ultramontanos".

susana3060@hotmail.com

\section{Resumen}

El presente artículo busca trazar un perfil de la historiadora Margarita González Pacciotti (1942-2008), destacando su formación intelectual, su desempeño docente e investigativo y, en general, su producción académica. Con base en un análisis sistemático de la bibliografía producida en el marco del giro historiográfico colombiano conocido como la Nueva Historia se pone en relación la obra de Margarita González con un contexto intelectual más amplio.

Palabras clave: Margarita González, historiografía colonial, historia intelectual.

\section{Abstract}

The purpose of this article is to present a picture of historian Margarita González Pacciotti (1942-2008), highlighting her intellectual formation, her performance as teacher and researcher, and her academic production in general. A systematic analysis of the bibliography produced within the framework of the historiographic turn in Colombia known as New History, relates Margarita González's work to a broader intellectual context.

Key words: Margarita González, colonial historiography, intellectual history.

Durante el año 2008, la muerte se llevó a algunos pioneros e innovadores de la moderna investigación y reflexión en ciencias sociales y humanas en Colombia: Orlando Fals Borda, Eduardo Umaña Luna, Danilo Cruz Vélez, Ramón Pérez Mantilla, Roberto Pineda Giraldo, Blanca Ochoa de Molina, Edith Jiménez de Muñoz y Margarita González Pacciotti. Cada uno de ellos, además de haber sido destacados investigadores y pensadores, fueron maestros, multiplicadores de su saber y conocimiento, que lo 
supieron transmitir a sus estudiantes en diferentes universidades como la Nacional de Colombia, los Andes y el Externado. Todos ellos requieren una nota de reconocimiento y recordación. En la presente me referiré a la inolvidable historiadora Margarita González (1942-2008).

La conocí en febrero de 1977, cuando llegó a dictarnos a los alumnos de tercer semestre de Antropología la cátedra de Historia de Colombia I. Desde un comienzo su particular forma de dictar el curso y expresarse, así como los énfasis que hacía en ciertos acontecimientos, me cautivaron; establecimos una relación que con el tiempo se transformó en una sincera amistad que mantuvimos durante treinta años. La clase comenzaba a la una y cuarto y terminaba unos minutos antes de las tres; eran casi dos horas en las que nos llevaba de su mano al pasado, a la Conquista y a la Colonia; su envidiable cultura y su evidente conocimiento de las temáticas que abordaba hacían que no quisiéramos que la clase se terminara.

En esos años, estudiar en la Universidad Nacional era una verdadera aventura, pues se sabía cuándo iniciaba el semestre, pero no cuándo terminaba. Normalmente un semestre duraba un año, por ello fue nuestra profesora entre 1977 y 1978. La única razón por la cual no dictaba clase era que en las inmediaciones de la universidad se presentara un enfrentamiento a piedra con la Fuerza Pública, promovida por algunos de los grupos políticos que allí hacían presencia; le temía, con pánico, a alguna de estas manifestaciones. Todavía está presente en mi memoria la vez que le quemaron el carro a un profesor francés que estaba en intercambio. No acabó de escucharse el estruendo cuando ella ya estaba en su Renault 4, arrancando para partir a su casa. Antes de dictar sus clases asistía religiosamente al antiguo Archivo Nacional, ubicado en el cuarto piso de la Biblioteca Nacional, como a esa inagotable fuente de información, y a la Biblioteca Luis Ángel Arango. Sus horas de paciente investigación se reflejaron en sus cátedras y en sus libros y ensayos.

El curso de Historia de Colombia I se centraba en la Conquista y la Colonia. La fundamentación de la clase estaba constituida por sus propios escritos: arrancaba con el "Bosquejo histórico de las formas del trabajo 
indígena", publicado en la desaparecida revista Cuadernos Colombianos (4, IV de trimestre de 1974). Allí desarrolló, de manera general, el problema de la integración de la población indígena al proceso económico colonial y los cambios que se impusieron por la progresiva disminución de tal mano de obra y por la aparición del mestizaje. La base documental fue un riguroso examen de las fuentes secundarias más destacadas sobre el tema, algunas de ellas de reciente publicación; otras poco conocidas por estar publicadas en otros idiomas, y las tradicionalmente consultadas (Gibson; Lewin; McGreevey; Ots; Rich; Simpson; Zabala).

Continuaba con su principal tema de investigación: el Resguardo en el Nuevo Reino de Granada (1970)', que retomaba de manera rigurosa lo que Juan Friede había desarrollado entre 1942 y 1944 y que no había vuelto a ser analizado sistemáticamente desde entonces. La investigación de Margarita González debe enmarcarse dentro del desarrollo de la reforma agraria en el país que desde comienzos de la década de los sesenta intentó implantar el Estado colombiano y que tocaba directamente a las comunidades indígenas. En la década de los cuarenta, la política del Departamento de Tierras y Aguas había obligado a varios jóvenes intelectuales a preocuparse por la suerte de esas parcialidades y había dado lugar a un indigenismo, de corte lascasiano, que fue en contravía del antiindigenismo que durante 450 años dominó la sociedad asentada en el territorio de la actual república de Colombia. A diferencia del clásico libro de Friede, el de nuestra profesora se centró en la Colonia, en la región cundiboyacense, y tiene como hilo conductor la estructura y el funcionamiento interno del resguardo, así como sus articulaciones con otros elementos de la vida colonial: la encomienda, las formas de trabajo indígena y la hacienda, pero deja abierta la posibilidad de otras investigaciones acerca de los contrastes regionales que adquirió la institución objeto de estudio.

1 En 1992, El Ancora Editores adelantó una tercera edición revisada y aumentada con los resultados de otras investigaciones realizadas por Margarita. 
Terminaba el curso con "El estanco colonial del tabaco", texto que había aparecido en el número 8, IV trimestre de 1975, de la mencionada revista Cuadernos Colombianos. Allí dio a conocer las nuevas condiciones que se suscitaron en la segunda mitad del siglo XVIII y que incidieron en el movimiento de la Independencia. Como lecturas de contexto y de permanente referencia recomendaba y citaba, con propiedad, algunos de los trabajos de Friede; la Introducción a la historia económica de Colombia, de Álvaro Tirado Mejía; los obligados libros de Magnus Morner y de Richard Konetzke; así como los de Jaime Jaramillo Uribe.

El curso de Historia de Colombia II trataba sobre la transición de la Colonia a la República, la Independencia y algunos aspectos del siglo XIX colombiano. Allí las lecturas fueron: un ensayo suyo, "El proceso de manumisión en Colombia” que, al igual que los anteriores, se editó en Cuadernos Colombianos 2, II trimestre de 1974², en el que centra su atención en los aspectos jurídico-políticos que antecedieron a la manumisión definitiva en 1851, que fue un excelente complemento al ensayo de Jaime Jaramillo Uribe "La controversia jurídica y filosófica librada en la Nueva Granada en torno a la liberación de los esclavos" (1965)³. Se completaba el ciclo de lecturas con dos ensayos de Jaime Jaramillo Uribe: "Esclavos y señores en la sociedad colombiana del siglo XVIII" y "Mestizaje y diferenciación social en la segunda mitad del siglo XVIII”; otros tomados del por entonces recién aparecido Colombia hoy (1978) y de la compilación hecha por Jesús Antonio Bejarano, El siglo XIX en Colombia visto por historiadores norteamericanos (1977).

2 Este ensayo fue republicado por Darío Jaramillo Agudelo, en el volumen 18 de la Biblioteca Básica Colombiana de Colcultura.

3 Este ensayo, junto con "Esclavos y señores en la sociedad colombiana del siglo XVIII" (1963), "La población indígena de Colombia en el momento de Conquista y sus trasformaciones posteriores" (1964) y "Mestizaje y diferenciación social en el Nuevo Reino de Granada en la segunda mitad del siglo XVIII" (1965), todos publicados en el Anuario Colombiano de Historia Social y de la Cultura, hacen parte del libro Ensayos sobre historia social colombiana. 
Al igual que en el curso anterior, conocimos algunas obras de connotados historiadores como Frank Safford y del mismo Bejarano. Al final de los dos cursos se tenía una idea aproximada acerca de algunos problemas de historia social, política y económica de la Conquista, la Colonia, la Independencia y el siglo XIX; para algunos, como fue mi caso, la preocupación por la historia colombiana comenzó a ser permanente y esto dio lugar a una serie de preguntas e inquietudes que desde entonces he tratado de explicarme.

Margarita era hija de un prestigioso abogado, que recién egresado viajó a especializarse en Italia, donde conoció a Edegueis Pacciotti, con quien se casó, regresó a Colombia y se radicó en Bogotá. Durante años, la señora Pacciotti fue la profesora de italiano de la Universidad Nacional, institución por la que sentía tal afecto que murió en 1986 prácticamente dictando clase. La preparación intelectual de Margarita y sus dos hermanas, Marina y Yolanda, fue especialmente exigente, en la que intervino activamente el padre; así lo sugiere la dedicatoria del libro sobre el resguardo. Dominaban el italiano, el inglés y el francés, la literatura y las artes; de hecho, Margarita interpretaba el piano, frecuentaba las salas de cine y cocinaba suculentos platos de comida italiana. Su formación se completó cuando en 1960 entró a estudiar Filosofía en la Universidad Nacional, donde desde un comienzo mostró una clara vocación de investigadora.

La formación allí recibida fue general, miscelánea si se quiere, ya que adquirió un conocimiento de la filosofía antigua y contemporánea, la lógica, las lenguas clásicas y modernas, matizada con la literatura, la historia, la sociología, la economía, etc., lo que para su posterior desarrollo fue importante. Junto con ella ingresaron a la facultad personas que también habrían de tener un destacado papel en las ciencias sociales y con quienes tendría relaciones que trascenderían el ámbito profesional: Jorge Orlando Melo, quien fue su esposo y el padre de sus dos hijos, Mauricio y Leonardo; Germán Colmenares, que estuvo casado con Marina González Pacciotti. Valga decir que Yolanda González fue compañera sentimental de Estanislao Zuleta. 
$\mathrm{Al}$ año siguiente ingresó a la facultad Jorge Palacios Preciado ${ }^{4}$. Unos y otros constituyeron el núcleo al que Jaime Jaramillo Uribe le inculcó el interés por la historia de Colombia, y les dio a conocer el magistral trabajo de Fernand Braudel, El mediterráneo en la época de Felipe II (1953), y otros más de la escuela de los Annales.

Por esa época el existencialismo estaba de moda y Margarita y Jorge Orlando fueron influidos por las ideas de Jean Paul Sartre; de hecho, Melo comenzó su trasegar intelectual con la traducción de Problemas de método y con un polémico ensayo sobre Sartre y el marxismo, donde fustigó el reduccionismo económico de la sociología marxista y su olvido del individuo y de las particularidades de los fenómenos históricos.

Colmenares, Melo, González Pacciotti y Palacios constituyeron, junto con Hermes Tovar Pinzón, Víctor Álvarez, alumnos ambos de la Facultad de Filosofía y de Jaime Jaramillo Uribe, Marco Palacios Rozo y Álvaro Tirado Mejía, el movimiento de la Nueva Historia colombiana que transformó en varios sentidos la forma de concebir, investigar y escribir la historia de Colombia, cuyos años dorados fueron los finales de los sesenta y toda la década del setenta.

La primera manifestación de la Nueva Historia fue Partidos politicos y clases sociales, de Germán Colmenares (1968); el manifiesto de lanzamiento fue Los estudios históricos en Colombia, de Jorge Orlando Melo (1969), y en el mismo año apareció el segundo libro de Colmenares, Las haciendas de los jesuitas en la Nueva Granada. En 1970 vio la luz el ya mencionado libro de Margarita González, El Resguardo en el Nuevo Reino de Granada; en los años siguientes aparecieron otros más.

4 Jaime Jaramillo Uribe, en sus Memorias intelectuales, recuerda entre sus alumnos de ese entonces a Gilma Mora de Tovar, Germán Rubiano Caballero, Carmen Ortega Ricaurte, Isabel Sánchez Méndez y Rubén Sierra Mejía. Los cuatro primeros se dedicaron igualmente a la historia, el profesor Sierra fue un destacado maestro de filosofía analítica e inglesa del posterior, 1966, Departamento de Filosofía de la Facultad de Ciencias Humanas. 
Aunque fue un grupo muy heterogéneo, la historia, como disciplina, se profesionalizó en el país, con el inició de sus labores con investigaciones sobre la Colonia. No es aventurado decir que tanto Margarita como Germán Colmenares y Jorge Orlando Melo, formados directamente con el profesor Jaramillo, y considerados por él como sus discípulos más queridos, se acercaron a las fuentes documentales tradicionales, pero con nuevas preguntas, formuladas a la luz de las diversas disciplinas de las ciencias sociales y humanas y de los debates que se daban en Latinoamérica y en Europa. Esto dio lugar a importantes y novedosos trabajos.

En general, los historiadores de la Nueva Historia centraron su atención en el estudio de la Colonia, el que emprendieron con novedosas metodologías e interpretaciones, y dentro de este grupo se destacó especialmente Germán Colmenares (1938-1990), quien sin lugar a dudas ha sido el más importante historiador colombiano. Se les ha criticado su evidente inclinación por los marcos económicos (Betancourt), lo que de alguna manera fue lógico, pues además del vigoroso auge que en las décadas del sesenta y setenta tuvo el marxismo, la Nueva Historia surgió como una respuesta a la Academia Colombiana de Historia y a la concepción apologética que esa institución había promovido desde su fundación, en 1902, en la que los aspectos económicos, entre otros, habían sido desatendidos o poco tenidos en cuenta.

Sin embargo, las reinterpretaciones y síntesis adelantadas por Colmenares (Partidos; Historia económica) y por Melo (Historia de Colombia) suministran un marco socioeconómico útil e ineludible para otras interpretaciones históricas de carácter cultural, político, etc. Cada uno de ellos se trazó su propio derrotero investigativo. El de Margarita incluyó el estudio de algunos aspectos de la Conquista y la Colonia, así como con relación a la Independencia se interesó por la figura Libertador Simón Bolívar. También quiso abordar la investigación del líder republicano Rafael Uribe Uribe, pero la vida no le alcanzó.

Margarita fue, además de una excelente profesora, investigadora y escritora, una verdadera pionera de la moderna investigación histórica 
de Colombia. Aparte de colaborar en las dos publicaciones insignes de la Nueva Historia, el Anuario Colombiano de Historia Social y de la Cultura y Cuadernos Colombianos ${ }^{5}$, colaboró con el Manual de historia de Colombia, la primera gran publicación colectiva del grupo coordinado por Jaime Jaramillo Uribe, con el capítulo "Rentas del Estado, 1750-1850"6. A diferencia de algunos de sus compañeros de generación, nunca quiso ocupar cargos burocráticos y se mantuvo como docente e investigadora; su pasión fue investigar y escribir. La única ocupación que tuvo, distinta a las mencionadas, fue la de directora del Anuario Colombiano de Historia Social y de la Cultura, entre 1979 y 1982, correspondiéndole la edición de los números 9 y 10. Нa sido la única mujer que ha dirigido la emblemática revista y fue la primera en publicar un artículo allí: "El resguardo minero de Antioquia", que presentó como ponencia en el Primer Congreso de Antropología, celebrado en Popayán, en octubre de 1978.

Sus trabajos fueron novedosos, verdaderos aportes a la reflexión histórica. Calladamente supo plantear nuevas preguntas que iban contra la historia oficial promovida por la Academia de Historia; sin embargo, nunca atacó a los académicos, simplemente los pasó por alto y cuando los necesitó los citó. Reconoció en Indalecio Liévano Aguirre un pilar importante para la moderna historia colombiana, quien fue el autor de Los grandes conflictos sociales y económicos de nuestra historia.

Los estudios de filosofía los terminó en 1963. Por ese tiempo contrajo matrimonio con Jorge Orlando Melo y ambos se vincularon, desde comienzos de 1964, como docentes a la Universidad Nacional, al recién formado por Jaime Jaramillo Uribe Departamento de Historia (1962), y colaboraron estrechamente con las labores que desde allí adelantó su

5 La revista Cuadernos Colombianos publicó su último número, el 12, en marzo de 1979. Allí Margarita publicó otro ensayo: "La hacienda colonial y los orígenes de la propiedad territorial en Colombia”, en el que analizó una serie de cambios en las estructura agraria colonial: de la encomienda y la mita a la expansión y consolidación de la hacienda en la segunda mitad del siglo XVII, teniendo siempre como eje las formas de trabajo y el proceso de mestizaje.

6 En 1989 se republicó en el marco del segundo gran trabajo colectivo: La nueva historia. 
maestro. Con la creación de la Facultad de Sociología, en 1959, y del Departamento de Historia; con la importante labor investigativa y editorial de la primera, y con la publicación del Anuario Colombiano de Historia Social y de la Cultura (1963), comenzó una nueva y definitiva época de las modernas ciencias sociales y humanas en el país. El Departamento de Historia y el Anuario fueron una respuesta ideada por Jaramillo al rechazo que hubo en 1961 por parte de las directivas de la Universidad Nacional a la erección de un Instituto de Investigaciones Históricas.

Dentro de sus labores académicas, a Margarita le correspondió la traducción, en colaboración con Melo, de la tesis doctoral, convertida en libro en 1954: The Santander Regime in Gran Colombia (El régimen de Santander en la Gran Colombia, 1966), de David Bushnell. Al terminar ese trabajo viajó, entre junio o julio de 1965, a la Universidad de Carolina del Norte a cursar sus estudios de Maestría en Historia, bajo la dirección del profesor Harold Bierck. Por un error en el proceso de edición del libro del profesor Bushnell, aparece como único traductor Jorge Orlando Melo, falta que él mismo señaló en su momento. Al regresar de Estados Unidos, en agosto de 1967, se reincorporó a la Universidad Nacional y además se vinculó a la Universidad de los Andes, donde era profesor Germán Colmenares. Los dos emprendieron, junto con Darío Fajardo Montaña, una recopilación de fuentes documentales existentes en el Archivo Nacional, sobre el régimen del trabajo indígena (transportes, minería, agricultura, salinas y obrajes y trabajo doméstico), durante los siglos XVI y XVII en el Nuevo reino de Granada, con una muestra más representativa en lo concerniente a minería y agricultura de Cundinamarca, Boyacá y Santander (Fuentes). Esa experiencia fue la base para algunos de sus posteriores escritos. Durante el proceso de investigación y publicación del volumen se presentaron conflictos, que significaron el distanciamiento entre Margarita y Colmenares.

Después de una corta permanencia en el Valle del Cauca y de ponerle fin a su relación matrimonial, retornó a la Universidad Nacional y participó con el intelectual Mario Arrubla en nuevos proyectos: la revista Cuadernos Colombianos, una serie de recopilaciones de las obras más representativas de algunos políticos colombianos, auspiciada por la Cáma- 
ra de Representantes. ${ }^{7}$ Arrubla y Zuleta, su compañero y amigo desde el colegio en Medellín, formaron y lideraron, en los años sesenta, una corriente marxista, la Organización Marxista Colombiana, que abogó por un "marxismo culto", que sin lugar a dudas interesó a muchos jóvenes estudiantes universitarios.

Durante esos años Arrubla tuvo a su cargo la Dirección de Divulgación Cultural de la Universidad Nacional, y gracias a su accionar se publicaron importantes trabajos de intelectuales y científicos del pasado y del momento; además, creó la Revista de la Dirección de Divulgación Cultural, que fue un importante sitio de reflexión de los profesores universitarios, aparte de publicar varios trabajos de reconocidos pensadores e intelectuales extranjeros. A partir de 1977, Arrubla formó parte de Editorial La Carreta, que reimprimió los trabajos de los más connotados historiadores de la Nueva Historia y entre ellos los de Margarita González. Mario Arrubla viajó en 1982, en calidad de diplomático y la relación entre él y Margarita se cortó.

Serios quebrantos de salud la obligaron a desvincularse temporalmente de la actividad docente y a buscar el apoyo familiar. Pese a las dificultades, intentó escribir algunos ensayos que le costaron mucho trabajo. Logró publicar en 1983 "La política económica virreinal en el Nuevo Reino de Granada”, en el que hace una serie de consideraciones sobre las medidas que los Borbón impulsaron en las colonias americanas durante la segunda mitad del siglo XVIII. En 1985, Bolivar y la independencia de Cuba, producto de su año sabático, que se centra en el proyecto bolivariano (1822-1830) de independizar a Cuba por medio de la unificación de fuerzas militares y políticas de diversos países hispanoamericanos, el que fue un trabajo novedoso de historia diplomática colombiana. En 1986, "Aspectos económicos de la administración pública en Colombia, 1820-1886”, que resume una serie de medidas y cambios económicos, especialmente fiscales, del período.

7 La colección se llamó: Pensadores Políticos Colombianos. Los volúmenes compilados fueron: Obras selectas de López Pumarejo (en colaboración con Mario Arrubla); Obras selectas. Alzate Avendaño y Obras selectas. Jorge Eliécer Gaitán. Todos aparecieron en 1978. 
Adelantó algunas traducciones: El ideal de lo práctico: el desafío de formar una élite técnica y empresarial en Colombia (1989), de Frank Safford, que adelantó junto con María Victoria Gussoni ${ }^{8}$. En alguna charla adelantada con el profesor Safford, en 1985, en el marco del V Congreso Colombiano de Historia, realizado en Armenia, me preguntó quién podía realizar esa traducción; sin pensarlo dos veces, le sugerí el nombre de Margarita. Según parece, mi recomendación surtió efecto. Para el Anuario Colombiano de Historia Social y de la Cultura hizo varias traducciones: "Acerca de las interpretaciones socioeconómicas de la política en Colombia del siglo: variaciones sobre un tema” (con María V. Gussoni), de Frank Safford, y "Campesinos y asalariados en la Zona Bananera de Santa Marta (1900-1935)”, de Catherine Legrand.

Se jubiló de la Universidad Nacional a mediados de los años noventa, y para terminar su ciclo en el Alma Máter publicó la trascripción de El vasallo instruido en el estado del Nuevo Reino de Granada y en sus respectivas obligaciones (2001), del sacerdote capuchino Fr. Joaquín de Finestrad, libro escrito en la década de 1780, que es producto de la visita pastoral a los pueblos sublevados durante la Rebelión de los Comuneros, presidida por el arzobispo virrey Antonio Caballero y Góngora y de la que fue miembro Finestrad, en el que se reivindica la monarquía española y se condena la sublevación. Margarita la completó con una excelente y bien documentada introducción sobre la rebelión comunera, las capitulaciones y la visita pastoral. Para adelantar ese trabajo, visitó con asiduidad la sección de Libros Raros y Curiosos, hoy Fondo Antiguo, de la Biblioteca Nacional de Colombia, en el que reposa el original. Frecuentemente nos encontrábamos allí, su salud había mejorado, pero en ocasiones se mostraba distante, pensativa.

En ese diciembre del 2001 me invitó a comer a su casa y me obsequió un ejemplar del recién publicado libro. Conocí a sus dos hijos y a

8 Título original en inglés: The Ideal of the Practical Colombia' Struggle to form a Technical Elite, University of Texas Press, 1976. La edición colombiana le correspondió a la Universidad Nacional y a El Áncora Editores. La traducción fue posible por la Fundación para la Promoción de la Investigación y la Tecnología. 
su querida nieta Carolina, hija de Mauricio, el mayor de ellos; ella había diseñado la portada y había realizado la armada electrónica del volumen del Vasallo. No fue la única ocasión en que preparó la edición de un texto histórico: en 1977 hizo lo propio con el libro de Tomás Cipriano de Mosquera sobre el Libertador Simón Bolívar ${ }^{9}$ para la colección Historia Viva que sostuvo por unos años el Instituto Colombiano de Cultura.

Se pensionó de la Universidad, pero no de la investigación. Se empeñó en estudiar la Independencia, especialmente los aspectos de la guerra. Se preocupó por muchos matices no siempre tenidos en cuenta como el de los armamentos, su calidad, eficacia, etc. Continuó sus pesquisas sobre el Libertador y adelantó para el Museo Nacional un trabajo sobre la formación intelectual de Bolívar, con particular atención en el aporte de Simón Rodríguez.

La publicación del Vasallo significó su retorno a la escritura, pues durante años, quizás desde 1985, se había negado a adquirir algún tipo de compromiso editorial, salvo la reedición de sus obras ${ }^{10}$. En 1998, el editor Camilo Calderón Schrader me invitó a colaborar en el proyecto Enciclopedia de Colombia (Océano Grupo Editorial, 2001) y como había un aparte sobre el Descubrimiento, la Conquista y la Colonia, pensamos que la mejor opción era la de Margarita. Inmediatamente me comuniqué con ella, concretamos una cita en el café OMA de la quince, y luego de agradecerme haber pensado en ella me dijo que no aceptaba, pues no se sentía en capacidad de afrontar un compromiso de tal responsabilidad.

9 La introducción “El Bolívar de Mosquera” se publicó en la revista Gaceta, editada también por Colcultura.

10 En 1977, la Editorial La Carreta recogió en un volumen titulado Ensayos de historia colombiana, tres de sus ensayos publicados en la revista Cuadernos Colombianos ("Bosquejo histórico de las formas del trabajo indígena", "El estanco colonial del trabajo" y "El proceso de manumisión en Colombia”). En 1984, El Ancora Editores publicó esos tres artículos, más uno, "La hacienda colonial y los orígenes de la propiedad territorial en Colombia", con el título de Ensayos de historia colonial colombiana, que fue reeditado en 1985 por Punto de Lectura, de la distribuidora y editora Aguilar, Altea, Taurus, Alfaguara, S. A. En 1979, La Carreta reeditó El resguardo en el Nuevo Reino de Granada. En 1992, El Ancora adelantó una tercera edición que, como se anotó, contó con una cuidadosa revisión de la autora. 
Para mí fue motivo de alegría recibir el volumen del Vasallo. En los años siguientes escribió, por lo menos, dos artículos más: "Bolívar y el arte de la guerra" y "La participación indígena en los comuneros", ambos publicados en la revista Al Margen, un nuevo proyecto editorial de Mario Arrubla, en combinación con los profesores Bernardo Correa y Guillermo Mina. Con alguna frecuencia asistía a algunos eventos sociales y conferencias de su interés, continuaba yendo al cine y a las exposiciones de arte que se presentaban en la ciudad.

En diciembre de 2005 fui a visitarla, la encontré muy bien, con mucho ánimo, orgullosa de sus dos hijos que vivían en Estados Unidos, inquieta por un próximo viaje de descanso que iba a realizar con Leonardo por las tierras comuneras de Santander, para terminar luego en La Ceja, en la casa de los abuelos Melo González; con ganas de hacer otras publicaciones; contenta con sus proyectos con el Museo Nacional. Con alegría me comentó que le había llevado a la Universidad de los Andes a su maestro, Jaime Jaramillo Uribe, sus recientes publicaciones, así mismo me hizo un significativo comentario sobre la excelente labor que venía cumpliendo Jorge Orlando en la Biblioteca Luis Ángel Arango.

Al poco tiempo yo enfermé y por espacio de dos años y medio o algo más no volví a saber de ella. Me la encontré en noviembre del 2008, en La Candelaria, su barrio. La acompañé al Son de los Grillos, adonde debía ella cumplir una cita para almorzar. La encontré pálida, un tanto desmejorada y fatigosa. Le prometí visitarla y llevarle un ejemplar de mi libro Juan Friede, 1901-1990: vida y obra de un caballero andante en el trópico que estaba próximo a salir. El día 30 de diciembre, abrí el periódico como a la una de la tarde y cuál no sería mi sorpresa al encontrar el aviso de su muerte, a causa de un fulminante cáncer detectado en estado avanzado unos días después de nuestro encuentro. La muerte de mi profesora, colega y amiga me causó un fuerte impacto. Las exequias fueron a las 12 del día, no pude asistir, lo que me dolió en el alma. No alcanzó a conocer el libro del que con frecuencia habíamos hablado en años anteriores. 


\section{Bibliografía}

Bejarano, Jesús Antonio, ed. "Campesinado, luchas agrarias e historia social: notas para un balance historiográfico". Anuario Colombiano de Historia Social y de la Cultura 11 (1983): 251-304.

---. El siglo XIX en Colombia visto por historiadores norteamericanos. Bogotá: La Carreta, 1977.

Betancourt Mendieta, Alexander. Historia y nación. Medellín: La Carreta Histórica, 2007.

Braudel, Fernand. El Mediterráneo y el mundo mediterráneo en la época de Felipe II. México; Buenos Aires: FCE, 1953.

Bushnell, David. El régimen de Santander en la Gran Colombia. Trad. Jorge Orlando Melo. Bogotá: Tercer Mundo-Facultad de Sociología, 1966.

Cataño, Gonzalo. “Jorge Orlando Melo: difusor de la Nueva Historia”. Revista Credencial Historia 115 (julio de 1999).

Colmenares, Germán. Historia económica y social de Colombia, 1537-1719. Bogotá: Universidad del Valle, 1973.

---Lashaciendas de los jesuitasen el Nuevo Reino de Granada: siglo XVIII. Bogotá: Universidad Nacional-Tercer Mundo, 1969.

---. Partidos politicos y clases sociales. Bogotá: Italgraf-Uniandes, 1968.

Colmenares, Germán, Darío Fajardo y Margarita de Melo. Fuentes coloniales para la historia del trabajo en Colombia. Bogotá: Universidad de los Andes, 1968.

Finestrad, Joaquín de. El vasallo instruido en el estado del Nuevo Reino de Granada y en sus respectivas obligaciones. Trasc. e introd. Margarita González. Bogotá: Facultad de Ciencias Humanas de la Universidad Nacional de Colombia, 2001.

Garrido, Margarita. "Germán Colmenares: renovador de la investigación histórica". Revista Credencial Historia 115 (julio de 1999).

Gibson, Charles. Los aztecas bajo el dominio español: 1519-1810. México: Siglo XXI, 1967.

González, Margarita. “La participación indígena en los comuneros”. Al Margen 14 (junio 2005).

---. "Bolívar y el arte de la guerra". Al Margen 11 (septiembre 2004).

---. El resguardo en el Nuevo Reino de Granada. Prólogo de Bernardo Tovar. Bogotá: El Áncora, 1992.

---. "Aspectos económicos de la administración pública en Colombia: 1820-1886". Anuario Colombiano de Historia Social y de la Cultura 13-14 (1985-1986): 63-90.

---. Bolivar y la Independencia de Cuba. Bogotá: El Ancora, 1985.

---. Ensayos de historia colonial colombiana. Bogotá: El Áncora, 1984.

---."La política económica virreinal en el Nuevo Reino de Granada 1750-1810". Anuario Colombiano de Historia Social y de la Cultura 11 (1983): 129-86. 
--- "La hacienda colonial y los orígenes de la propiedad territorial en Colombia". Cuadernos Colombianos 3.12 (marzo 1979): 569-90.

---. "El resguardo minero de Antioquia." Anuario Colombiano de Historia Social y de la Cultura 9 (1979): 17-38.

---. "Las rentas del Estado". Manual de historia de Colombia. Vol. 2. Director Científico Jaime Jaramillo Uribe. Bogotá: Instituto Colombiano de Cultura, 1979.

--- "Movimientos revolucionarios en América a fines del siglo XVIII". Revista de Extensión Cultural 5 (julio-agosto 1978): 129.

---Obrasselectas. Gilberto Alzate Avendaño.t.7.Bogotá: Cámara de Representantes, 1978.

---. Obras selectas. Jorge Eliécer Gaitán. t. 5. Bogotá: Cámara de Representantes, 1978.

---. "El Bolívar de Mosquera”. Gaceta 1.12-13 (julio-agosto 1977).

---. Ensayos de historia colombiana. Bogotá: Editorial La Carreta, 1977.

---. El proceso de manumisión en Colombia. Vol. 18. Bogotá: Instituto Colombiano de Cultura, 1976.

---. "Bosquejo histórico de las formas del trabajo indígena". Cuadernos Colombianos 4 (trimestre 4, 1974).

González, Margarita y Mario Arrubla, comps. Obras selectas de López Pumarejo. t. 10. Bogotá: Cámara de Representantes, 1978.

Jaramillo Agudelo, Darío, comp. La nueva historia de Colombia. Bogotá: Instituto Colombiano de Cultura, 1976.

Jaramillo Uribe,Jaime, comp.Ensayossobre historia social colombiana. Bogotá: Universidad Nacional, 1968.

---. Memorias intelectuales. Bogotá: CESO-Universidad de los Andes-Tauros, 2007.

---. "Reseña de Fuentes para la historia del trabajo en Colombia, por Germán Colmenares, Margarita de Melo y Darío Fajardo". Anuario Colombiano de Historia Social y de la Cultura 5 (1970): 209.

Konetzke, Richard. América Latina II: la época colonial. Madrid: Siglo Veintiuno, 1972.

---. Descubridores y conquistadores de América. Madrid: Gredos, 1968.

LeGrand, Catherine. "Campesinos y asalariados en la zona bananera de Santa Marta (1900-1935)". Trad. Margarita González. Anuario Colombiano de Historia Socialy de la Cultura 11 (1983): 235-50.

Lewin, Boleslao. La rebelión de Tupac Amaru y los orígenes de la Independencia de Hispanoaméricana. Buenos Aires: Sociedad Editora Latinoamericana, 1967.

Liévano Aguirre, Indalecio. Los grandes conflictos sociales y económicos de nuestra historia. 2 vols. Bogotá: Tercer Mundo, 1968.

McGreevey. William. Tierray trabajo en Nueva Granada: 1760-1845. Berkeley: Universidad de California, 1968. 
MDGL. "Reseña de El Resguardo en el Nuevo Reino de Granada, por Margarita González". Anuario Colombiano de Historia Social y de la Cultura 6-7 (1971-1972): 225.

Melo González, Jorge Orlando. Historia de Colombia: la dominación española. Bogotá: La Carreta, 1977.

---. "La literatura histórica en la última década”. Boletín Cultural y Bibliográfico 25.15 (1988).

--- "Los estudios históricos en Colombia 1969-1979". Revista de Extensión Cultural 9-10 (sep-dic 1980; ene-abr 1981): 100-4.

Mörner, Magnus. La Corona española y los foráneos en los pueblos de indios de América. Estocolmo: Almgvist and Wiksell, 1970.

---. La mezcla de razas en la historia de América Latina. Buenos Aires: Paidós, 1969.

Ots Capdequi, José María. Nuevos aspectos del siglo XVIII español en América. Bogotá: Centro, 1946.

Rich, E. E. "Colonial Settlement and its Labour Problems". The Cambridge Economic History of Europe. vol. 4. Londres: Cambridge University Press, 1967.

Rueda Enciso, José Eduardo. Juan Friede, 1901-1990: vida y obra de un caballero andante en el trópico. Bogotá: Instituto Colombiano de Antropología e Historia, 2008.

---. "La antigua Facultad de Sociología de la Universidad Nacional y la creación de los departamentos de Antropología en Colombia (notas para un debate)". Los imaginarios y la cultura popular. Bogotá: CEREC-CODER, 1993.

Safford, Frank. "Acerca de las interpretaciones socioeconómicas de la política en la Colombia del siglo XIX”. Trad. Margarita González y María Victoria Gussoni. Anuario Colombiano de Historia Social y de la Cultura 13-14 (1985-1986): 91-152.

---. El ideal de lo práctico: el desafío de formar una élite técnica y empresarial en Colombia. Trad. Margarita González y María Victoria Gussoni. Bogotá: Universidad Nacional-El Áncora, 1989.

Simpson, Lesley. Los conquistadores y el indio americano. Barcelona: Península, 1970.

Tirado Mejía, Álvaro. Introducción a la historia económica de Colombia. Bogotá: Universidad Nacional de Colombia, 1971.

Tovar Zambrano, Bernardo. "El pensamiento historiador colombiano sobre la época colonial”. Anuario Colombiano de Historia Social y de la Cultura 10 (1982): 5-118.

---. "Reseña de El resguardo en el Nuevo Reino de Granada, por Margarita González". Anuario Colombiano de Historia Social y de la Cultura 9 (1979): 153-5.

Zabala, Silvio. La encomienda indiana. Madrid: Centro de Estudios Históricos, 1935.

Fecha de recepción: 27 de febrero de 2009.

Fecha de aprobación: 16 de marzo de 2009. 